\title{
Sex differences in choice-based thermal nociceptive tasks in adult rats
}

\author{
Bourgeois, JR and Kopec, AM
}

Dept. of Neuroscience \& Experimental Therapeutics, Albany Medical College, Albany, NY

\begin{abstract}
Interest in the role of sex as a biological variable continues to increase, including a mandate for the study of both sexes in NIH-funded research. Choice-based thermal nociceptive tests allow for the study of a more spontaneous response to thermal stimuli and avoidance behavior compared to traditional nociceptive assays, and their usage has been increasing in recent years. However, to date no comparison of naïve male and female responses to such tests has been published. As sex differences are known to exist in both human chronic pain conditions and rodent models of nociception, it is critical to understand the impact of sex on any nociceptive assay. Herein, we examined the effect of sex on two choice-based thermal nociceptive tests, the thermal gradient test and the temperature place preference test, in adult rats. We report that marked sex differences exist in responses to these tests. Namely, the activation of a $10^{\circ} \mathrm{C}$-to- $47^{\circ} \mathrm{C}$ thermal gradient results in an increase in time spent in the $10^{\circ} \mathrm{C}$ zone in females, compared to a reduction in males. In a temperature place preference test pairing a surface temperature of $22^{\circ} \mathrm{C}$ with either $5^{\circ} \mathrm{C}, 10^{\circ} \mathrm{C}, 47^{\circ} \mathrm{C}$, or $50^{\circ} \mathrm{C}$, males spent less than $50 \%$ of their time in every non- $22^{\circ} \mathrm{C}$ zone, but in females this was only observed when testing $50^{\circ} \mathrm{C}$. Together, these results suggest that male rats show more avoidance behavior to non-ambient temperatures when given free access to multiple zones, including at temperatures which are milder than those typically used to evoke a nociceptive response in traditional hot and cold plate tests.
\end{abstract}

\section{INTRODUCTION}

The treatment of chronic pain remains a public health challenge, with approximately $20.4 \%$ of Americans experiencing chronic pain [1], defined as pain lasting longer than three months [2]. There are numerous tasks of thermal nociception with which to study animal models exhibiting a pain phenotype, with the hot plate test being among the most frequently used. The hot plate test is typically used to dissect the basic mechanisms of thermal nociception, to model hyperalgesia or allodynia observed in painful conditions, or to assess the efficacy of analgesics [3-7]. The cold plate test is used to model cold-based nociception, although its use is less frequent than the hot plate test, and the resulting behavior is often less pronounced [8-11]. While these tests measure responsive behavior such as paw withdrawal latency, paw licking, or jumping, these outcomes rely on experimenter interpretation, introducing some subjectivity. Such responsive behaviors, while informative, are considerably simplistic compared to the interaction of biological, psychological, and social aspects of human pain perception, particularly as it applies to chronic pain [12-16]. Additionally, the surface temperatures required to evoke an obvious response are often relatively extreme, e.g. $\geq 50{ }^{\circ} \mathrm{C}$ or $\leq 5^{\circ} \mathrm{C}$ for hot and cold plate tests, respectively, necessitating the use of trial cutoff times to prevent tissue damage $[3,5,6,8,9$, 17].

As an expansion of and complement to hot/cold plate tests, alternative assays to evaluate thermosensation which incorporate an element of choice have become more common in recent years, including the thermal gradient test, the thermal place preference test, and the Rotterdam Advanced Multiple Plate (RAMP) method [18-24]. These choice-based assays make use of flooring with a minimum of two discrete thermal zones and almost always include a non- 
noxious ambient zone, to which the animal has free access. The measured outcome of choicebased thermal assays is usually time spent in each zone, rather than nocifensive behaviors as identified by experimenters. Choice-based thermal assays provide an opportunity to observe behavior at less extreme temperatures which are not typically identified as aversive.

Studies of pain in humans indicate sex differences in the presentation of numerous chronic pain conditions. Specifically, complex regional pain syndrome (CRPS), fibromyalgia, rheumatoid arthritis, migraine headaches, lower back pain, and irritable bowel syndrome, among others, are all reported more frequently in females [25-32]. Sex differences exist in both the presentation and severity of pain, with females more commonly reporting neuropathic pain lasting more than three months and a higher percentage describing their chronic pain as "significant" than males [33,34]. Sex differences in the experience of thermal pain also exist in healthy humans, with females showing increased sensitivity to both hot and cold temperatures [35-40]. In rodent models of thermal pain, traditional hot plate studies give conflicting results in sensitivity to aversive heat stimuli, with some studies showing no difference and others showing either males or females as being more sensitive to hot temperatures [5, 17, 41-44]. To our knowledge, no direct comparisons between male and female rats in response to the cold plate test have been published. Although choice-based thermal nociception assays are increasingly used in use in rodent pain models, typically only one sex is tested.

Here, we show evidence that sex differences are present in behavioral responses to two choice-based thermal assays: the thermal gradient test and the two-temperature preference test. In addition, we find that choice-based thermal assays may uncover evidence of avoidance behavior at less extreme temperatures than are typically observed in traditional hot and cold plate tests.

\section{METHODS}

Animal model: Adult male and female Sprague-Dawley rats were purchased to be breeding pairs (Harlan/Envigo) and were group-housed with ad libitum access to food and water. Colonies were maintained on a 12:12 light:dark cycle (lights on at 07:00) and cages were changed twice per week. Litters were culled to a maximum of 12 pups between postnatal day (P)2 and P5, and at P21 pups were weaned into same sex pair-housing. To reduce the impact of any litter-specific effects, no more than two animals per sex were used from any single litter for the same experiment. All animals were approximately 3 months old at the time of experiments. Experiments and animal care were approved by the Institutional Animal Care and Use Committees at Albany Medical College.

Thermal gradient test: All tests were completed between the hours of 07:00-11:00 or 15:00-19:00 to minimize sleep cycle disruption. Prior to any behavioral testing, animals were handled on 3 occasions of $\sim 5$ minutes each in the behavioral testing suite, and animals were given at least 30 minutes to acclimate to the behavioral suite prior to testing. The thermal gradient chamber (Bioseb, BIO-GRADIENT) is a $10 \mathrm{~cm} \times 120 \mathrm{~cm}$ enclosed rectangular chamber with opaque walls and a metal floor. An area of $\sim 10 \mathrm{~cm} \times 12 \mathrm{~cm}$ on each end is positioned atop a cold or hot plate, creating surface temperatures of $10^{\circ} \mathrm{C}$ and $47^{\circ} \mathrm{C}$, respectively, at the ends of the chamber floor. The remaining $\sim 96 \mathrm{~cm}$ of the chamber floor is not in direct contact with an underlying temperature plate. Although the surface area within ambient zone was not uniform (as a result of proximity to either the hot or cold plates), areas adjacent to the hot or cold zones but not directly over the temperature plates quickly regressed to ambient temperatures which would not be considered noxious (see Supplemental Fig. 1 for temperature distribution), and thus time spent within this area was binned. Animals were given open access within the chamber, and movement was tracked via overhead camera. On day 1, animals were placed in 
the chamber for 30 minutes with the entire chamber at ambient temperature to determine initial zone preference. On day 2, temperature plates were turned on to create a temperature gradient, and the test was repeated. Day 2 results are expressed as the percentage change of time spent within a given zone, compared to average baseline preference for that group.

Thermal place preference test: Animals were placed on an apparatus (Bioseb, BIO$\mathrm{T} 2 \mathrm{CT}$ ) containing two independently controlled temperature plates. One plate was maintained at a surface temperature of $22^{\circ} \mathrm{C}$, while a second plate was set to a surface temperature of either $5^{\circ} \mathrm{C}, 10^{\circ} \mathrm{C}, 47^{\circ} \mathrm{C}$, or $50^{\circ} \mathrm{C}$. Animals were allowed to move freely between the plates for 10 minutes, which was tracked via overhead camera, to determine the time spent in each temperature zone. Results for each experiment are reported as three separate outcomes: time spent in non- $22^{\circ} \mathrm{C}$ zone, number of entrances into the non- $22^{\circ} \mathrm{C}$ zone, and average time spent in non- $22^{\circ} \mathrm{C}$ zone per entrance.

Statistics: No single animal was used for all experiments, but most were used for 3-4 of 5 possible experiments. Each animal was subjected to only one test per day. Animals with outcomes greater than two standard deviations above or below the mean were excluded as outliers. For the thermal gradient test, change from baseline within any temperature zone following thermal gradient activation was the outcome used to determine outliers, and all thermal gradient data from such animals were excluded from all analyses, resulting in the exclusion of two animals. For the thermal place preference test, all data from any animal were excluded at a given temperature if any of the outcomes were more than two standard deviations from the mean, resulting in the exclusion of $25^{\circ} \mathrm{C}$ tests, $210^{\circ} \mathrm{C}$ tests, $247^{\circ} \mathrm{C}$ tests, and $350^{\circ}$ $\mathrm{C}$ tests. Thermal gradient tests were analyzed using two-way ANOVAs (sex $\mathrm{x}$ temperature) with Tukey's multiple comparisons post-hoc test. Between sex and within-sex comparisons of thermal place preference tests were analyzed using two-way ANOVAs (sex x temperature) with Tukey's multiple comparisons post-hoc test. Additionally, to determine whether a temperature evoked avoidance behavior, for each temperature we compared the time spent in the non- $22^{\circ} \mathrm{C}$ zone for each sex with results expected by chance using a one sample t-test. Statistical significance is defined as $p<0.05$.

\section{RESULTS}

Sex differences in temperature preference in the thermal gradient test

In an initial 30-minute test with the entire thermal gradient at ambient temperature, there were no significant differences between or within sex for any zone (two-way ANOVA, $n=8-10$ animals/group) (Fig. 1A). The following day, animals underwent another 30-minute test with the hot and cold zones activated, and the percent change in time spent in each zone compared to group baseline averages was calculated. A main effect of temperature $\left(F_{(2,48)}=15.74, p<0.0001\right.$, $\mathrm{n}=8-10$ animals/group) and an interaction between sex and temperature $\left(F_{(2,48)}=12.10\right.$, $p<0.0001$ ) were observed (Table 1). In response to the activation of the thermal gradient, males increased time spent in the ambient zone, and decreased time spent in both the hot $(p=0.0028$, Tukey's multiple comparisons post hoc analysis) and cold zones $(p=0.0047)$. In females, activation of the thermal gradient resulted in decreased time spent in the hot zone and increased time spent in both the cold $(p<0.0001)$ and ambient zones $(p=0.0111)$. A significant difference in response to thermal gradient activation was observed between males and females, with females increasing time spent in the cold zone compared to decreased time in the cold zone in males ( $p=0.0009)$ (Fig. 1B).

Sex differences in temperature preference in the thermal place preference test 
To test preferences when given a direct choice between two thermal zones, we then conducted a series of thermal place preference tests allowing animals free access for 10 minutes between a $22^{\circ} \mathrm{C}$ zone and relatively cold or hot zone. Animals were tested at surface temperatures of $10^{\circ} \mathrm{C}$ and $47^{\circ} \mathrm{C}$, as were used in the thermal gradient test, as well as more extreme cold and hot temperatures $\left(5^{\circ} \mathrm{C}\right.$ and $50^{\circ} \mathrm{C}$, respectively). Main effects of both sex $\left(F_{(1,71)}=22.01, \quad p<0.0001\right.$, two-way ANOVA, $n=9-10$ animals/group) and temperature $\left(F_{(3,71)}=15.63, p<0.0001\right)$ were observed in the time spent in each non-22 ${ }^{\circ} \mathrm{C}$ zone (Table 1). Males spent significantly less time in the $50^{\circ} \mathrm{C}$ zone compared to the $10^{\circ} \mathrm{C}$ zone $(p=0.0008$, Tukey's multiple comparisons post hoc analysis). Comparing across all tests, males spent significantly less time in the $50^{\circ} \mathrm{C}$ zone compared to the $10^{\circ} \mathrm{C}$ zone $(p=0.0008$, Tukey's multiple comparisons post hoc analysis), while females spent less time in the $50^{\circ} \mathrm{C}$ zone compared to the $5^{\circ} \mathrm{C}$ zone $(p=0.0085)$, the $10^{\circ} \mathrm{C}$ zone $(p<0.0001)$, and the $47^{\circ} \mathrm{C}$ zone $(p=0.0168)$. Additionally, males spent less time than females in the $47^{\circ} \mathrm{C}$ zone $(p=0.0419)$ (Fig 2A). Main effects of both sex $\left(F_{(1,71)}=12.86, p=0.0006\right)$ and temperature $\left(F_{(3,71)}=3.591, p=0.0177\right)$ were also observed in the number of entrances made into the non-22 ${ }^{\circ} \mathrm{C}$ zones (Table 1), although no within-sex or within-temperature differences reached statistical significance after post-hoc analysis (Fig. 2B). Finally, main effects of sex $\left(F_{(1,71)}=8.173, p=0.0056\right)$ and temperature $\left(\mathrm{F}_{(3,71)}=11.30, p<0.0001\right)$ were observed in the amount of time spent in each non$22^{\circ} \mathrm{C}$ zone per entrance (Table 1). Males showed a reduction in time spent per entrance in the $50^{\circ} \mathrm{C}$ zone compared to the $10^{\circ} \mathrm{C}$ zone $(p=0.0350)$. Females showed a reduction in time spent per entrance into the $50^{\circ} \mathrm{C}$ zone compared to the $5^{\circ} \mathrm{C}$ zone $(p=0.0076)$ and the $10^{\circ} \mathrm{C}$ zone $(p=0.0012)$, but not the $47^{\circ} \mathrm{C}$ zone, although a non-significant trend was present in this comparison $(p=0.0527)$ No sex differences were observed in time spent in thermal zones per entrance (Fig. 2C).

Between a $22^{\circ} \mathrm{C}$ zone and a $10^{\circ} \mathrm{C}$ zone, males spent less time in the $10^{\circ} \mathrm{C}$ zone than expected by chance ( $p=0.0080$, one sample t-test, $n=10$ animals/group), while female results did not differ from chance (Fig. 3A). Similarly, when given the choice between a $22^{\circ} \mathrm{C}$ zone and a $47^{\circ} \mathrm{C}$ zone, males spent less time in the $47^{\circ} \mathrm{C}$ zone than predicted by chance $(p<0.0001)$, while females did not (Fig. 3B). When given a choice between a $22^{\circ} \mathrm{C}$ and a $5^{\circ} \mathrm{C}$ zone, males spent less time in the $5^{\circ} \mathrm{C}$ zone than expected by chance $(p<0.0001)$, while females did not (Fig. 3C). Finally, between a $22^{\circ} \mathrm{C}$ and a $50^{\circ} \mathrm{C}$ zone, both males and females spent less time in the $50^{\circ} \mathrm{C}$ zone than expected by chance ( $p<0.0001$ for both, one sample t-test) (Fig. 3D).

\section{DISCUSSION}

Herein, we examined the behavior of male and female adult rats in two different choicebased thermal tests. Consistent with their behavior in the thermal gradient test, males exhibited avoidance behavior of $10^{\circ}$ and $47^{\circ} \mathrm{C}$ in the thermal place preference test, as well as more extreme $5^{\circ}$ and $50^{\circ} \mathrm{C}$. These results in male rats indicate aversive behavior at temperatures which are milder than those typically used in traditional hot and cold plate tests [3, 8-10, 45]. In contrast, females exhibited a cold preference in the thermal gradient test, and only avoided the $50^{\circ} \mathrm{C}$ zone in the thermal gradient test, indicating an overall greater tolerance for both hot and cold temperatures. Collectively, these data are particularly interesting when compared with thermal nociception data in humans, which indicate higher sensitivity in healthy females to both hot and cold temperatures [35-40].

While traditional hot and cold plate tests have proved useful over decades of research, such tests rely on observer interpretation of reaction to a thermal stimulus. In the hot plate test, the measured reaction is frequently latency to respond, which is typically identified by paw lifting/licking or jumping. Cold plate tests generally produce a less pronounced response, and as 
a result outcomes are frequently measured as total response behaviors over a set amount of time, often several minutes. Observer interpretation requires a clear all-or-none response, temperatures are often set at a level designed to produce this effect. As a result, the risk of tissue damage is present, particularly in the case of the hot plate test, which may use temperatures as high as $58^{\circ} \mathrm{C}$. Cutoff times must be implemented to reduce this possibility, especially when testing analgesics which may prevent the response required to end the test [3, $5,8,11]$. Additionally, the introduction of an unescapable (and usually extreme) nociceptive thermal stimulus introduces an element of stress for the animal, which may present as a confounding variable in interpreting the results [46, 47]. The use of choice-based thermal nociception assays can serve to supplement the vast existing body of research on thermal nociception by examining the effects of a thermal stimulus on typical exploratory behavior. Such assays may therefore be particularly relevant to the study of chronic pain in humans, which involves a more complex interaction of biological and behavioral factors. Indeed, given the known sex differences in pain perception in humans, animal models of human pain must consider that psychological and social factors may exacerbate any underlying sex differences in human pain biology [12-14]. For example, catastrophizing, a negative mental state brought on by both actual and anticipated pain which often accompanies human chronic pain states and can impact the experience of clinical and experimental pain, is reported more commonly in women than men [15, 16, 48]. In light of this, sex differences in choice-based thermosensation assays may become particularly relevant due to their focus on anticipation and avoidance of discomfort, rather than the supraspinal reflex and nocifensive responses typically studied with hot and cold plate tests $[6,49]$. While a paw withdrawal or lick as a reaction to an unavoidable noxious stimulus can be used to indicate a nociceptive response, in isolation it provides no information as to how the presence of such a stimulus may influence future behavior. Thus, the operant response of stimulus avoidance can provide important insight into how males and females are affected differently in chronic pain models [50]. Therefore, discrepancies in results between nociceptive assays which rely on reflexive responses versus assays which rely on more proactive avoidance behavior, particular in the context of sex differences, may provide valuable insights and hypotheses into the mechanisms driving them. Our data provide the first comparison of naïve male and female rodent behavior in these tests.

\section{Sex differences in temperature-induced behavior}

The thermal place preference test involves only two thermal plates which are placed directly adjacent, with the entire apparatus enclosed in a clear plexiglass box, allowing for an interpretation of how a single temperature can influence behavior when paired with a nonnoxious temperature choice in rats. Using this assay at the relatively mild cold and hot temperatures of the $10^{\circ} \mathrm{C}$ and $47^{\circ} \mathrm{C}$, respectively, clear sex differences were observed in the response. Specifically, females spent $\sim 72.0 \%$ more time in the $47^{\circ} \mathrm{C}$ zone compared to males (Fig. 2A). While males spent less than $50 \%$ of their time in both the $10^{\circ} \mathrm{C}$ and $47^{\circ} \mathrm{C}$ zone, in females the time spent in each of these zones was not significantly different from chance (Fig. 3A, 3B). This suggests that these temperatures are considered aversive to males, but not females, when presented in the context of a choice.

Using the thermal place preference test to compare males and females at more extreme temperatures, such as those typically used in traditional cold and hot plate tests, sex differences were still observed. Similar to the results seen at $10^{\circ} \mathrm{C}$, males spent less time in the $5^{\circ} \mathrm{C}$ zone than expected by chance, whereas females did not (Fig. 3C). Interestingly, this aversion shown by males to both $5^{\circ} \mathrm{C}$ and $10^{\circ} \mathrm{C}$ in the thermal place preference test is at odds with published literature on naïve adult male behavior in the cold plate test. Specifically, multiple studies indicate a lack of response by naïve adult males to a $10^{\circ} \mathrm{C}$ cold plate, considering it nonnoxious, with $5^{\circ} \mathrm{C}[9,51]$ or $3^{\circ} \mathrm{C}[8]$ identified as the cutoff for noxious cold. Similarly, Kato, et 
al. identified a $10^{\circ} \mathrm{C}$ cold plate test as appropriate for identifying cold allodynia, with $4^{\circ} \mathrm{C}$ appropriate for identifying hyperalgesia, in an oxaliplatin-induced cold hypersensitivity model [10]. However, when assessing naive adult rats in a thermal place preference test against a $25^{\circ}$ $\mathrm{C}$ plate, Balayssac, et al. found $17^{\circ} \mathrm{C}$ as the cutoff below which rats would spend less time in the cold zone, with time spent in $5^{\circ} \mathrm{C}$ and $10^{\circ} \mathrm{C}$ zones being roughly equivalent to one another (but both below the time spent in $17^{\circ} \mathrm{C}$ ) [52]. While Kato, et al. found evidence of oxaliplatininduced allodynia (at $10^{\circ} \mathrm{C}$ ) and hyperalgesia (at $4^{\circ} \mathrm{C}$ ) using a cold plate test, Balayssac, et al. found no effect of oxaliplatin at either $5^{\circ} \mathrm{C}$ or $10^{\circ} \mathrm{C}$ using a thermal place preference test. This suggests that while an oxaliplatin treatment is sufficient to evoke a behavioral response (in Kato et al.'s case, hind paw withdrawal) in a cold plate test, it is not sufficient to alter behavior in a more spontaneous choice-based test. To the best of our knowledge, no data have been published on the cold temperatures considered noxious to naïve adult female rats.

In contrast to our results at $5^{\circ} \mathrm{C}$, our thermal place preference test examining more extreme heat at $50^{\circ} \mathrm{C}$ shows aversive behavior in both sexes. Indeed, $50^{\circ} \mathrm{C}$ was the only temperature of four tested in which females spent less time in the non-22 $\mathrm{C}$ zone than expected by chance (Fig. 3D). This temperature also showed sex differences in terms of withinsex comparisons to other temperatures tested. Namely, when given the choice between a $22^{\circ} \mathrm{C}$ and a second zone with a temperature of either $5^{\circ} \mathrm{C}, 10^{\circ} \mathrm{C}, 47^{\circ} \mathrm{C}$, or $50^{\circ} \mathrm{C}$, males showed reduced time spent in the $50^{\circ} \mathrm{C}$ compared only to the $10^{\circ} \mathrm{C}$ zone, while females spent less time in the $50^{\circ} \mathrm{C}$ zone than in the $5^{\circ}, 10^{\circ}$, and $47^{\circ} \mathrm{C}$ zones (Fig. 2A). Similarly, while the time spent in the $50^{\circ} \mathrm{C}$ zone per entrance was only reduced compared to $10^{\circ} \mathrm{C}$, females showed reduced time spent per entrance in the $50^{\circ} \mathrm{C}$ zone relative to both $5^{\circ}$ and $10^{\circ} \mathrm{C}$ (Figure $3 \mathrm{C}$ ). The fact that females spent less than half of their time in the $50^{\circ} \mathrm{C}$, while this was not the case with the $47^{\circ} \mathrm{C}$ zone, is unsurprising. Indeed, temperatures of $\geq 50^{\circ} \mathrm{C}$ are typically used for hot plate tests, with the more rarely used $48^{\circ} \mathrm{C}$ being considered the lower end of the range of appropriate temperatures [3]. However, this still leaves an interesting discrepancy between male and female responses to the thermal place preference test at both $47^{\circ} \mathrm{C}$ and $50^{\circ} \mathrm{C}$, as male behavior in this assay indicated avoidance behavior at $47^{\circ} \mathrm{C}$ (below the temperatures typically used to induce a nocifensive response), whereas no such behavior was seen in females.

\section{$\underline{\text { Sex differences in response to competing interests }}$}

The thermal gradient apparatus lends itself to the study of competing aversive interests. The thermal gradient test allows animals open exploration of a metal floor, enclosed in an opaque chamber with a clear plexiglass lid. While this setup allows for animals to spend time in preferred temperature zones, the presence of enclosed corners at each end (corresponding with the $10^{\circ} \mathrm{C}$ to $47^{\circ} \mathrm{C}$ zones) adds the variable of differing levels of potential exposure. In the absence of varied thermal stimuli, it should be expected that rodents would choose to spend more time in regions that provide more cover, as is typically seen in open field and elevated plus-maze tests [53-55]. Indeed, when the thermal gradient is not activated, both males and females spend a disproportionately reduced amount of time in the area designated as the ambient zone. Specifically, males and females spent only $35.7 \%$ and $41.8 \%$ of their exploratory time, respectively, in the ambient zone, despite the surface area of this zone accounting for $80 \%$ of the gradient floor (Fig. 1A; Supplemental Fig. 1). As a result, when the gradient is activated, the thermal gradient test should not be thought of as a strictly thermal test, but rather one of competing preferences between non-aversive temperatures and areas that may be perceived to provide increased protection. Although no differences in time spent within a given zone were observed between sexes with the gradient off, the activation of a thermal gradient led to different responses based on sex. Specifically, males spent reduced time in both the cold and hot zones, increasing their time spent in the more exposed ambient zone. In contrast, females responded to thermal gradient activation by reducing their time spent in the hot zone while 
increasing their time spent in the cold zone (Fig. 1B). This may be interpreted in different ways. First, it is possible that females find the level of exposure present in the ambient zone more aversive than males, causing them to tolerate the aversive cold zone. However, naïve adult females have previously been shown to be more willing than males to enter and remain in the center zone of in a large open field test, and in the open arms of an elevated plus maze test, as well as showing a reduction in overall fear and anxiety-like behavior, suggesting that their lack of a shift to the ambient zone may not be due to an increased fear of exposure [53-55]. Alternatively, it is possible that males find the $10^{\circ} \mathrm{C}$ cold zone more aversive than females do, and thus were more willing to increase their time in the more exposed ambient zone. This interpretation is supported by the differences in behavior observed between sexes in the $10^{\circ} \mathrm{C}$ vs. $22^{\circ} \mathrm{C}$ thermal place preference test. The fact that females spend equal time in both zones, together with their shift to the $10^{\circ} \mathrm{C}$ zone in an activated thermal gradient, indicates that the $10^{\circ}$ $\mathrm{C}$ surface temperature in the thermal gradient is less aversive to females than increasing time in the more exposed ambient zone. The observed behavior of males shifting their preference to the more exposed ambient zone rather than the cold zone in the activated thermal gradient is also consistent with their behavior in the $10^{\circ} \mathrm{C}$ vs. $22^{\circ}$ thermal place preference test, which collectively suggest the $10^{\circ} \mathrm{C}$ surface temperature is more aversive in males.

To summarize, we identified sex differences in responses to hot and cold temperatures in two choice-based thermosensation assays in naïve adult rats. These findings may aid in the design of future studies using choice-based tests to study nociceptive responses in various rodent pain models, as well as identifying how incorporating an element of choice in nociceptive assays may reveal additional differences in behavior beyond the traditionally studied withdrawal responses. 
Figure 1

A

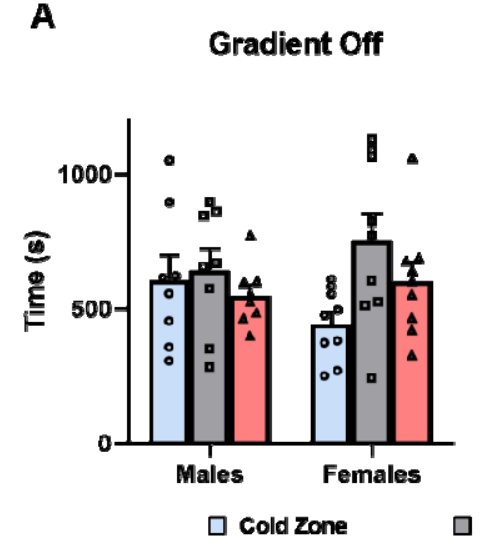

B

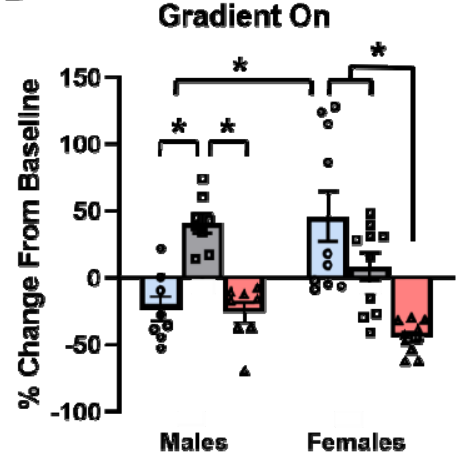

$\square$ Hot Zone

Figure 1 - Sex differences in the thermal gradient test.

Males and females show different responses to the choice between hot, cold, and ambient thermal zones. (A) With the entire gradient at ambient temperature, no sex differences exist in the amount of time spent in each zone, nor is any within-sex preference observed between zones (two-way ANOVA, $n=8-10$ animals per group). (B) Following activation of the thermal gradient, males and females respond differently. Males reduced time spent in the cold and hot zones and increased time spent in the ambient zone, while females reduced time spent in the hot zone and increase time spent in the cold zone $\left({ }^{*}=p<0.05\right.$, two-way ANOVA with Tukey's multiple comparisons post hoc analysis, main effect of temperature: $p<0.001$; interaction between sex and temperature: $p<0.0001, n=8-10$ per group). 
Figure 2

A

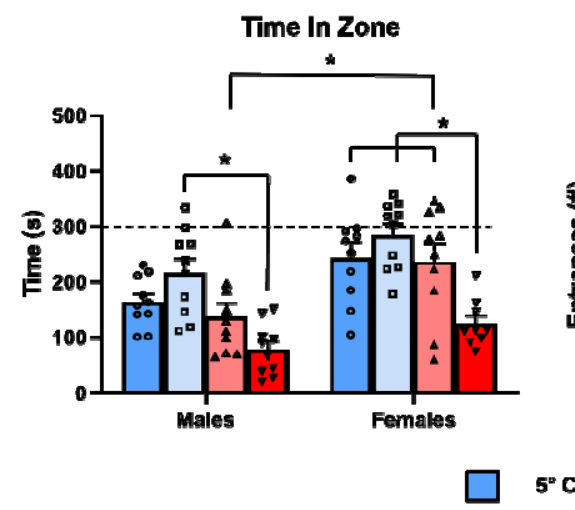

B

Entrances Into Zone

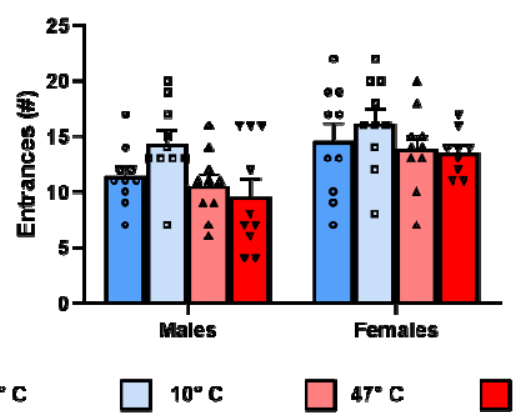

c

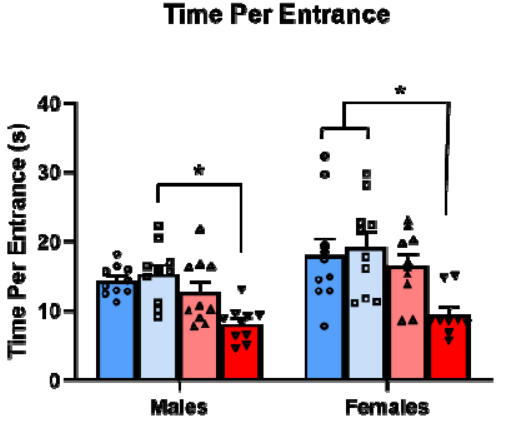

Figure 2: Sex differences in thermal place preference test at more extreme temperatures.

In a 10-minute thermal place preference test, $(\mathbf{A})$ males spent more time in the $10^{\circ} \mathrm{C}$ zone than the $50^{\circ} \mathrm{C}$ zone, while females spent more time in the $5^{\circ} \mathrm{C}, 10^{\circ} \mathrm{C}$, and $47^{\circ} \mathrm{C}$ zones than the $50^{\circ}$ $\mathrm{C}$ zone. Additionally, males spent less time in the $47^{\circ} \mathrm{C}$ zone than females. (B) No differences were observed in the number of entrances into any zone between males and females, nor between different temperatures in within-sex comparisons. (C) Males spent more time per entrance in the $10^{\circ} \mathrm{C}$ zone than the $50^{\circ} \mathrm{C}$ zone, while females spent more time per entrance in the $5^{\circ} \mathrm{C}$ and $10^{\circ} \mathrm{C}$ zones than the $50^{\circ} \mathrm{C}$ zone. $\left({ }^{*}=p<0.05\right.$, two-way ANOVA with Tukey's multiple comparisons post hoc analysis, $n=9-10$ animals per group). 
Figure 3
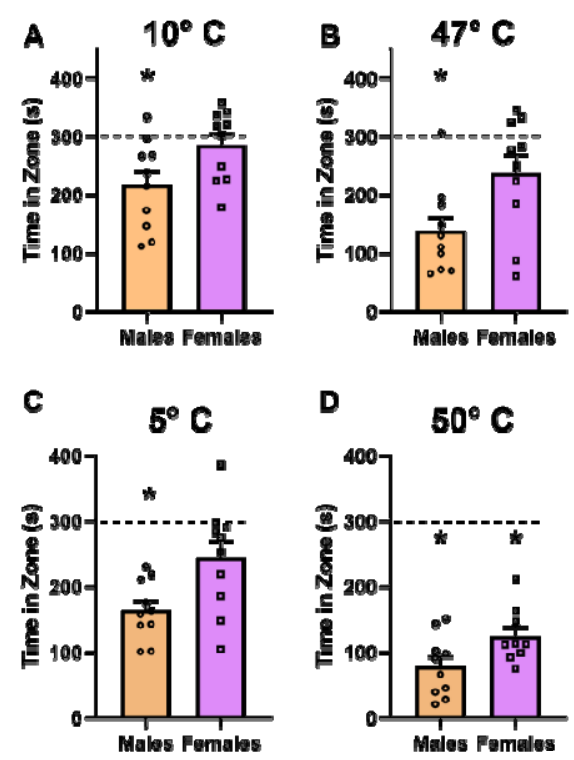

Figure 3: Sex differences in aversion in the thermal place preference test.

In a 10-minute thermal place preference test, males spent less than $50 \%$ of their time in the (A) $10^{\circ} \mathrm{C},(\mathrm{B}) 47^{\circ} \mathrm{C}$, and $(\mathrm{C}) 5^{\circ} \mathrm{C}$ zones when given the choice between these temperatures and a $22^{\circ} \mathrm{C}$ zone. Females did not show this response. (D) Both males and females spent less time in the $50^{\circ} \mathrm{C}$ zone than expected by chance $\left({ }^{*}=p<0.05\right.$, one sample t-test; $n=9-10$ animals per group). 
Supplemental Figure 1

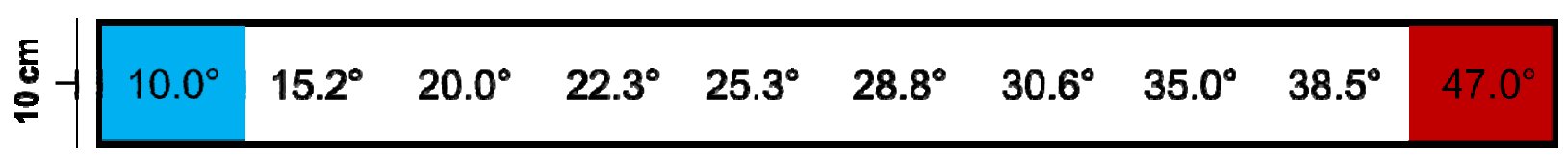

$120 \mathrm{~cm}$

\section{Supplemental Figure 1: Schematic of thermal gradient chamber (top view)}

Representation of floor surface temperatures throughout the thermal gradient chamber, as depicted from above. Blue and red areas represent the portion directly overlaying cold and hot plates, respectively. The ambient zone (shown in white) was divided into 8 sections measuring $10 \mathrm{~cm} \times 12 \mathrm{~cm}$ each, and surface temperature was obtained in the center of each section. 
Table 1

\begin{tabular}{|l|c|c|c|c|}
\hline Assay & Outcome & $\begin{array}{c}\text { Main Effect of } \\
\text { Sex }\end{array}$ & $\begin{array}{c}\text { Main Effect of } \\
\text { Temperature }\end{array}$ & Interaction \\
\hline $\begin{array}{l}\text { Thermal Gradient } \\
\text { (Off) }\end{array}$ & Time in Zones & $\begin{array}{c}\mathrm{F}_{(1,48)}<0.0001 \\
p=0.9993\end{array}$ & $\begin{array}{c}\mathrm{F}_{(2,48)}=2.195 \\
p=0.1224\end{array}$ & $\begin{array}{c}\mathrm{F}_{(2,48)}=1.471 \\
p=0.2398\end{array}$ \\
\hline $\begin{array}{l}\text { Thermal Gradient } \\
\text { (On) }\end{array}$ & $\begin{array}{c}\text { \% Change in } \\
\text { Preference }\end{array}$ & $\begin{array}{c}\mathrm{F}_{(1,48)}=0.4400 \\
p=0.5103\end{array}$ & $\begin{array}{c}\mathrm{F}_{(2,48)}=12.10 \\
p<0.0001\end{array}$ & $\begin{array}{c}\mathrm{F}_{(2,48)}=15.74 \\
p<0.0001\end{array}$ \\
\hline $\begin{array}{l}\text { Thermal Place } \\
\text { Preference }\end{array}$ & $\begin{array}{c}\text { Time in Non-22 } \\
\text { Zones }\end{array}$ & $\begin{array}{c}\mathrm{F}_{(1,71)}=22.01 \\
p<0.0001\end{array}$ & $\begin{array}{c}\mathrm{F}_{(3,71)}=15.63 \\
p<0.0001\end{array}$ & $\begin{array}{c}\mathrm{F}_{(3,71)}=0.4921 \\
p=0.6889\end{array}$ \\
\hline $\begin{array}{l}\text { Thermal Place } \\
\text { Preference }\end{array}$ & $\begin{array}{c}\text { Entrances into Non- } \\
\mathbf{2 2}{ }^{\circ} \mathrm{C} \text { Zones }\end{array}$ & $\begin{array}{c}\mathrm{F}_{(1,71)}=12.86 \\
p=0.0006\end{array}$ & $\begin{array}{c}\mathrm{F}_{(3,71)}=3.591 \\
p=0.0177\end{array}$ & $\begin{array}{c}\mathrm{F}_{(3,71)}=0.2805 \\
p=0.8393\end{array}$ \\
\hline $\begin{array}{l}\text { Thermal Place } \\
\text { Preference }\end{array}$ & $\begin{array}{c}\text { Time Per Entrance } \\
\text { into Non-22 }{ }^{\circ} \mathrm{C} \text { Zones }\end{array}$ & $\begin{array}{c}\mathrm{F}_{(1,71)}=8.173 \\
p=0.0056\end{array}$ & $\begin{array}{c}\mathrm{F}_{(3,71)}=11.30 \\
p<0.0001\end{array}$ & $\begin{array}{c}\mathrm{F}_{(3,71)}=0.3027 \\
p=0.8234\end{array}$ \\
\hline
\end{tabular}

\section{Table 1: Statistical main effects and interactions}

1. Zelaya, C.E., J.M. Dahlhamer, J.W. Lucas, E.M. Connor., Chronic Pain and High-impact Chronic Pain Among U.S. Adults, 2019, C.f.D.C.a.P.N.C.f.H. Statistics, Editor. 2020: NCHS Data Brief.

2. Treede, R.D., et al., A classification of chronic pain for ICD-11. Pain, 2015. 156(6): p. 1003-1007.

3. Barrot, M., Tests and models of nociception and pain in rodents. Neuroscience, 2012. 211: p. 3950.

4. Bates, M.L., et al., Social environment alters opioid-induced hyperalgesia and antinociceptive tolerance in adolescent mice. Eur J Pain, 2016. 20(6): p. 998-1009.

5. Cicero, T.J., B. Nock, and E.R. Meyer, Gender-related differences in the antinociceptive properties of morphine. J Pharmacol Exp Ther, 1996. 279(2): p. 767-73.

6. Deuis, J.R., L.S. Dvorakova, and I. Vetter, Methods Used to Evaluate Pain Behaviors in Rodents. Front Mol Neurosci, 2017. 10: p. 284.

7. Vendruscolo, L.F., F.A. Pamplona, and R.N. Takahashi, Strain and sex differences in the expression of nociceptive behavior and stress-induced analgesia in rats. Brain Res, 2004. 1030(2): p. 277-83.

8. Jasmin, L., et al., The cold plate as a test of nociceptive behaviors: description and application to the study of chronic neuropathic and inflammatory pain models. Pain, 1998. 75(2-3): p. 367-82.

9. Allchorne, A.J., D.C. Broom, and C.J. Woolf, Detection of cold pain, cold allodynia and cold hyperalgesia in freely behaving rats. Mol Pain, 2005. 1: p. 36. 
10. Kato, Y., et al., Gosha-jinki-gan reduced oxaliplatin-induced hypersensitivity to cold sensation and its effect would be related to suppression of the expression of TRPM8 and TRPA1 in rats. Anticancer Drugs, 2014. 25(1): p. 39-43.

11. Bennett, G.J. and Y.K. Xie, A peripheral mononeuropathy in rat that produces disorders of pain sensation like those seen in man. Pain, 1988. 33(1): p. 87-107.

12. Cho, C., H.K. Deol, and L.J. Martin, Bridging the Translational Divide in Pain Research: Biological, Psychological and Social Considerations. Front Pharmacol, 2021. 12: p. 603186.

13. Gatchel, R.J., et al., The biopsychosocial approach to chronic pain: scientific advances and future directions. Psychol Bull, 2007. 133(4): p. 581-624.

14. Edwards, R.R., et al., The Role of Psychosocial Processes in the Development and Maintenance of Chronic Pain. J Pain, 2016. 17(9 Suppl): p. T70-92.

15. Meints, S.M. and R.R. Edwards, Evaluating psychosocial contributions to chronic pain outcomes. Prog Neuropsychopharmacol Biol Psychiatry, 2018. 87(Pt B): p. 168-182.

16. Unruh, A.M., Gender variations in clinical pain experience. Pain, 1996. 65(2-3): p. 123-67.

17. Imanaka, A., et al., Neonatal tactile stimulation reverses the effect of neonatal isolation on openfield and anxiety-like behavior, and pain sensitivity in male and female adult Sprague-Dawley rats. Behav Brain Res, 2008. 186(1): p. 91-7.

18. Descoeur, J., et al., Oxaliplatin-induced cold hypersensitivity is due to remodelling of ion channel expression in nociceptors. EMBO Mol Med, 2011. 3(5): p. 266-78.

19. Delfini, M.C., et al., TAFA4, a chemokine-like protein, modulates injury-induced mechanical and chemical pain hypersensitivity in mice. Cell Rep, 2013. 5(2): p. 378-88.

20. Moqrich, A., et al., Impaired thermosensation in mice lacking TRPV3, a heat and camphor sensor in the skin. Science, 2005. 307(5714): p. 1468-72.

21. Tappe-Theodor, A. and R. Kuner, Studying ongoing and spontaneous pain in rodents--challenges and opportunities. Eur J Neurosci, 2014. 39(11): p. 1881-90.

22. Walczak, J.S. and P. Beaulieu, Comparison of three models of neuropathic pain in mice using a new method to assess cold allodynia: the double plate technique. Neurosci Lett, 2006. 399(3): p. 240-4.

23. Chen, L., et al., Conditional knockout of NaV1.6 in adult mice ameliorates neuropathic pain. Sci Rep, 2018. 8(1): p. 3845.

24. Duraku, L.S., et al., Rotterdam Advanced Multiple Plate: a novel method to measure cold hyperalgesia and allodynia in freely behaving rodents. J Neurosci Methods, 2014. 224: p. 1-12.

25. Greenspan, J.D., et al., Studying sex and gender differences in pain and analgesia: a consensus report. Pain, 2007. 132 Suppl 1: p. S26-S45.

26. de Mos, M., et al., The incidence of complex regional pain syndrome: a population-based study. Pain, 2007. 129(1-2): p. 12-20.

27. Sandroni, P., et al., Complex regional pain syndrome type I: incidence and prevalence in Olmsted county, a population-based study. Pain, 2003. 103(1-2): p. 199-207.

28. Lleo, A., et al., Is autoimmunity a matter of sex? Autoimmun Rev, 2008. 7(8): p. 626-30.

29. White, K.P., et al., The London Fibromyalgia Epidemiology Study: the prevalence of fibromyalgia syndrome in London, Ontario. J Rheumatol, 1999. 26(7): p. 1570-6.

30. Sandler, R.S., Epidemiology of irritable bowel syndrome in the United States. Gastroenterology, 1990. 99(2): p. 409-15.

31. Leonardi, M., et al., The global burden of migraine: measuring disability in headache disorders with WHO's Classification of Functioning, Disability and Health (ICF). J Headache Pain, 2005. 6(6): p. $429-40$.

32. Lipton, R.B., et al., Prevalence and burden of migraine in the United States: data from the American Migraine Study II. Headache, 2001. 41(7): p. 646-57. 
33. Smith, B.H., et al., The impact of chronic pain in the community. Fam Pract, 2001. 18(3): p. 292-9.

34. Bouhassira, D., et al., Prevalence of chronic pain with neuropathic characteristics in the general population. Pain, 2008. 136(3): p. 380-387.

35. Neziri, A.Y., et al., Reference values of mechanical and thermal pain tests in a pain-free population. Eur J Pain, 2011. 15(4): p. 376-83.

36. Magerl, W., et al., Reference data for quantitative sensory testing (QST): refined stratification for age and a novel method for statistical comparison of group data. Pain, 2010. 151(3): p. 598-605.

37. Waller, R., et al., Pressure and cold pain threshold reference values in a large, young adult, painfree population. Scand J Pain, 2016. 13: p. 114-122.

38. Hashmi, J.A. and K.D. Davis, Noxious heat evokes stronger sharp and annoying sensations in women than men in hairy skin but not in glabrous skin. Pain, 2010. 151(2): p. 323-329.

39. Ferreira-Valente, M.A., J.L. Pais-Ribeiro, and M.P. Jensen, Validity of four pain intensity rating scales. Pain, 2011. 152(10): p. 2399-2404.

40. Klatzkin, R.R., B. Mechlin, and S.S. Girdler, Menstrual cycle phase does not influence gender differences in experimental pain sensitivity. Eur J Pain, 2010. 14(1): p. 77-82.

41. Mogil, J.S., et al., Sex differences in thermal nociception and morphine antinociception in rodents depend on genotype. Neurosci Biobehav Rev, 2000. 24(3): p. 375-89.

42. South, S.M., S.R. Edwards, and M.T. Smith, Antinociception versus serum concentration relationships following acute administration of intravenous morphine in male and female Sprague-Dawley rats: differences between the tail flick and hot plate nociceptive tests. Clin Exp Pharmacol Physiol, 2009. 36(1): p. 20-8.

43. Ali, B.H., S.I. Sharif, and A. Elkadi, Sex differences and the effect of gonadectomy on morphineinduced antinociception and dependence in rats and mice. Clin Exp Pharmacol Physiol, 1995. 22(5): p. 342-4.

44. Lima, M., et al., Sex-related long-term behavioral and hippocampal cellular alterations after nociceptive stimulation throughout postnatal development in rats. Neuropharmacology, 2014. 77: p. 268-76.

45. Sapio, M.R., et al., Haploinsufficiency of the brain-derived neurotrophic factor gene is associated with reduced pain sensitivity. Pain, 2019. 160(5): p. 1070-1081.

46. Butler, R.K. and D.P. Finn, Stress-induced analgesia. Prog Neurobiol, 2009. 88(3): p. 184-202.

47. Jennings, E.M., et al., Stress-induced hyperalgesia. Prog Neurobiol, 2014. 121: p. 1-18.

48. Jensen, I., et al., Coping with long-term musculoskeletal pain and its consequences: is gender a factor? Pain, 1994. 57(2): p. 167-172.

49. Giglio, C.A., et al., Behavioral and physiological methods for early quantitative assessment of spinal cord injury and prognosis in rats. Braz J Med Biol Res, 2006. 39(12): p. 1613-23.

50. Datta, S., et al., Behavioral and anatomical characterization of the bilateral sciatic nerve chronic constriction (bCCl) injury: correlation of anatomic changes and responses to cold stimuli. Mol Pain, 2010. 6: p. 7.

51. Tanimoto-Mori, S., et al., Pharmacologic investigation of the mechanism underlying cold allodynia using a new cold plate procedure in rats with chronic constriction injuries. Behav Pharmacol, 2008. 19(1): p. 85-90.

52. Balayssac, D., et al., Assessment of thermal sensitivity in rats using the thermal place preference test: description and application in the study of oxaliplatin-induced acute thermal hypersensitivity and inflammatory pain models. Behav Pharmacol, 2014. 25(2): p. 99-111.

53. Toufexis, D.J., K.M. Myers, and M. Davis, The effect of gonadal hormones and gender on anxiety and emotional learning. Horm Behav, 2006. 50(4): p. 539-49.

54. Knight, P., et al., Sex differences in the elevated plus-maze test and large open field test in adult Wistar rats. Pharmacol Biochem Behav, 2021. 204: p. 173168. 
bioRxiv preprint doi: https://doi.org/10.1101/2021.11.28.470257; this version posted November 28, 2021. The copyright holder for this preprint (which was not certified by peer review) is the author/funder, who has granted bioRxiv a license to display the preprint in perpetuity. It is made available under aCC-BY-NC-ND 4.0 International license.

55. Johnston, A.L. and S.E. File, Sex differences in animal tests of anxiety. Physiol Behav, 1991. 49(2): p. $245-50$. 